\title{
Impact of Zinc, Glutathione, and Polyphenols as Antioxidants in the Immune Response against SARS-CoV-2
}

\author{
José Manuel Pérez de la Lastra ${ }^{1, *(D)}$, Celia Andrés-Juan ${ }^{2}$, Francisco J. Plou ${ }^{3}\left(\mathbb{D}\right.$ and Eduardo Pérez-Lebeña ${ }^{4}$ \\ 1 Biotechnology of Macromolecules Research Group, Instituto de Productos Naturales y Agrobiología, \\ IPNA-CSIC, 38206 San Cristóbal de la Laguna, Spain \\ 2 Instituto CINQUIMA and Departamento de Química Orgánica, Facultad de Ciencias, \\ Universidad de Valladolid, 47011 Valladolid, Spain; celia.andres.juan@uva.es \\ 3 Instituto de Catálisis y Petroleoquímica, CSIC, 28049 Madrid, Spain; fplou@icp.csic.es \\ 4 Sistemas de Biotecnología y Recursos Naturales, 47625 Valladolid, Spain; info@glize.eu \\ * Correspondence: jm.perezdelalastra@csic.es; Tel.: +34-9222-60112
}

check for

updates

Citation: Pérez de la Lastra, J.M.;

Andrés-Juan, C.; Plou, F.J.;

Pérez-Lebeña, E. Impact of Zinc,

Glutathione, and Polyphenols as

Antioxidants in the Immune Response against SARS-CoV-2. Processes 2021, 9 , 506. https://doi.org/10.3390/ pr9030506

Academic Editor: Dionysios

V. Chartoumpekis

Received: 26 February 2021

Accepted: 8 March 2021

Published: 11 March 2021

Publisher's Note: MDPI stays neutral with regard to jurisdictional claims in published maps and institutional affiliations.

Copyright: (C) 2021 by the authors Licensee MDPI, Basel, Switzerland. This article is an open access article distributed under the terms and conditions of the Creative Commons Attribution (CC BY) license (https:/ / creativecommons.org/licenses/by/ $4.0 /)$.

\begin{abstract}
SARS-CoV-2, the coronavirus triggering the disease COVID-19, has a catastrophic health and socioeconomic impact at a global scale. Three key factors contribute to the pathogenesis of COVID-19: excessive inflammation, immune system depression/inhibition, and a set of proinflammatory cytokines. Common to these factors, a central function of oxidative stress has been highlighted. A diversity of clinical trials focused predominantly on antioxidants are being implemented as potential therapies for COVID-19. In this study, we look at the role of zinc, glutathione, and polyphenols, as key antioxidants of possible medicinal or nutritional significance, and examine their role in the antiviral immune response induced by SARS-Cov-2. An unresolved question is why some people experience chronic COVID and others do not. Understanding the relationship between SARS-CoV-2 and the immune system, as well as the role of defective immune responses to disease development, would be essential to recognize the pathogenesis of COVID-19, the risk factors that affect the harmful consequences of the disease, and the rational design of successful therapies and vaccinations. We expect that our research will provide a novel perspective that contributes to the design of clinical or nutritional targets for the prevention of this pandemic.
\end{abstract}

Keywords: zinc; glutathione; polyphenols; flavonoids; ROS scavengers; immunity; SARS-COv-2; COVID-19

\section{Introduction}

Molecular oxygen $\left(\mathrm{O}_{2}\right)$ provides adenosine triphosphate (ATP) through its reduction to $\mathrm{H}_{2} \mathrm{O}$ by mitochondrial respiration complexes of aerobic species. The by-products of cellular respiration are reactive oxygen species (ROS), comprised of free radical compounds, such as superoxide $\left(\mathrm{O}^{2-}\right)$, hydroxyl radicals $(\mathrm{HO} \cdot)$, lipid hydroperoxides, and reactive non-radical compounds, such as hydrogen peroxide $\left(\mathrm{H}_{2} \mathrm{O}_{2}\right)$, hypochlorous acid $(\mathrm{HOCl})$, and ozone $\left(\mathrm{O}_{3}\right)$. Under normal conditions, it is estimated that $2 \%$ of the oxygen consumed by an aerobic cell diversifies towards the generation of reactive species. These reactive species carrying unpaired valence-shell electrons are fragile and, inside the cells, tend to capture electrons from other molecules in their vicinity, including DNA, lipids, and proteins. Such associations can inactivate target molecules irreversibly [1]. ROS development in the mitochondria is the main source of ROS in mammalian cells. Reactive oxygen species (ROS) catalysts include peroxidases, NADPH oxidase, nitric oxide synthase (NOX) isoforms, xanthine oxidase, lipoxygenases, glucose oxidase, and myeloperoxidase [2]. Low to intermediate levels of ROS have beneficial effects on many physiological mechanisms, such as killing invading microorganisms, the wound healing process, and tissue regeneration [3]. However, in high amounts, ROS can lead to cell death. Therefore, aerobic organisms have evolved antioxidant machinery to regulate the amounts of various reactive ROS species 
to prevent cellular damage. These antioxidant enzymes and molecules are designed to scavenge or prevent free radicals. ROS-scavenging enzymes include superoxide dismutase, glutathione peroxidase, glutathione-reductase, catalase, and superoxide reductase [4]. These enzymes are encoded by the antioxidant gene network and are found in virtually all organelles.

As we age, the rate of generation of reactive oxygen species by mitochondria, the main source of their production, increases [5]. The increased production of these species inflicts injury to the inner membrane of the mitochondria, which by a positive feedback mechanism induces an increase in the generation of reactive species. As mitochondria are the most important source of reactive oxygen species, it is obvious that mitochondrial DNA is more exposed than nuclear DNA to severe oxidative damage that can lead to mutations and deletions in its own strand. The lower energy production would affect cell function, and on the other hand, the alteration in the electronic transport chain would increase the rate of generation of reactive oxygen species. In this case, the localized alteration would be aggravated by causing subsequent damage to mitochondrial DNA $[5,6]$. Changes to the equilibrium of ROS production (Figure 1) and the potential to sustain a high degree of antioxidant resistance contributes to oxidative stress. Therefore, cells have sophisticated DNA repair systems. Additionally, they are related to the decrease in the number of mitochondria, a typical characteristic of aging cells [6]. The changes in the diet leading to a reduction in the generation of reactive oxygen species by the mitochondria is presented as one of the most effective antioxidants means to ensure good health and even prolong life [7].

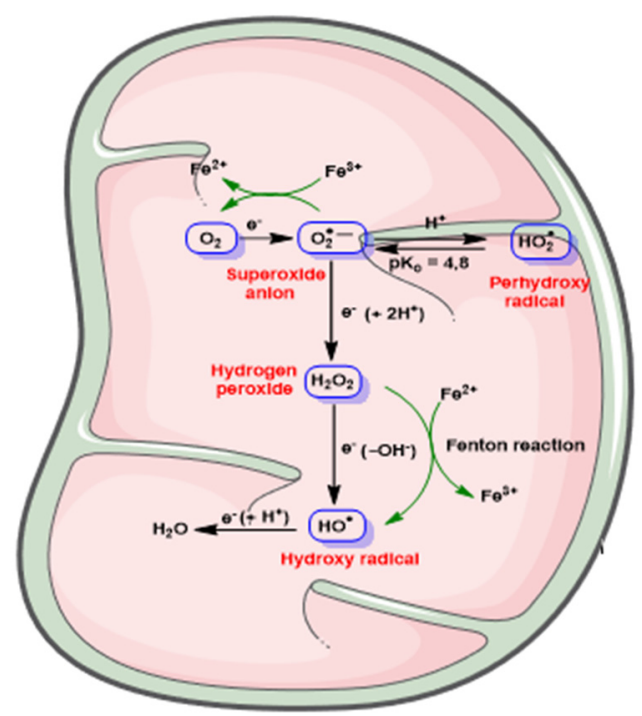

Figure 1. Schematic reactions leading to the production of reactive oxygen species (ROS) in the mitochondria.

The immune system must function very rapidly and accurately to remove SARSCoV-2 just over minutes after exposure, keeping it from spreading and colonizing the lungs and cardiovascular system. This rapid reaction is mediated by the innate immune system's natural killer (NK) cells [8]. Evidence suggests that their dysfunction is related to the severity of acute respiratory syndrome. In the most vulnerable populations (e.g., elder, obese, or overweight individuals), COVID-19 results in a cytokine storm and the production of ROS. It is therefore imperative to gain in-depth knowledge of the critical activators of disease severity to minimize mortality and hospitalization rates that drive abnormal host response. One question that remains to be answered is why some people suffer from chronic COVID-19 disease and others do not. This review examines the role of key antioxidants of possible medicinal or nutritional significance in the antiviral immune response induced by SARS-Cov-2. Particularly, we examine the antioxidants 
zinc, glutathione, and polyphenols as determinants of the immune response triggered by SARS-Cov-2 [9].

\section{Virus-Induced Oxidative Damage}

Viruses are not considered living organisms, but they need a host cell to develop and survive. ROS is important for its physiological function because viruses are intracellular parasites based upon the biosynthesis mechanisms of their host cells [10]. ROS are generated by several cellular processes and can be overproduced in reaction to a broad range of cellular stimuli. The ROS generated during virus infection have critical effects on both the virus and host cells. ROS can mediate a cross-talk between the main cell pathways that are triggered during an viral infection [10]. The tissue toxicity and reactivity of ROS triggered by excess immune reactions against viral diseases can clarify the injury mechanisms found in the different viral diseases involving immune interactions [11]. Cells may be able to defend themselves from oxidative damage using different endogenous pathways, such as those regulated by superoxide dismutase and catalase, which catalytically degrade superoxide and hydrogen peroxide, respectively. Oxidation induces protein, lipids, and DNA destruction, which may contribute to cell death. The cascade of events induced by the oxidative stress condition of SARS-CoV-2 infection leads to the severity of the host disease. Respiratory viral infections have been associated with inhibition of the nuclear factor (erythroid-derived 2)-like 2 (NRF2)-mediated pathways and NF- $\mathrm{kB}$ signaling activation, which may promote inflammation and oxidative damage during these infections [12,13]. Under physiological conditions, mitochondrial ROS (mtROS) are critical players in the regulation of immune signaling pathways. This occurs through increased mtROS production in plasmacytoid dendritic cells (pDCs), which are key producers of type I interferons (IFN-I) and coordinators of antiviral immunity. The robust type I IFN development of pDCs is essential for the clearance of some acute viral infections. The possible regulatory role of mtROS on the antiviral signaling pathways can be initiated by receptors localized to different cellular compartments. Endosomal Toll-like receptors (TLRs) in pDCs mediates the early phase of IFN-I production whereas the late phase of type I IFN response can be triggered by cytosolic retinoic acid-inducible gene I (RIG-I) stimulation [14].

\section{ROS in the Pathophysiology of COVID-19}

COVID-19 is caused by SARS-CoV-2, which belongs to the sub-family of betacoronaviruses. They are enveloped, positive single-stranded, large RNA viruses [15]. COVID-19 pathogenesis is not well known, but is likely to be multifactorial, contributing in severe cases to a systemic hyperinflammatory reaction and related thromboembolic complications [16]. As seen with other life-threatening conditions associated with acute viral infections, they might be correlated with a reduction in antioxidant defense, as well as neutrophil invasion and release of ROS. During host-virus interactions of SARS-CoV-2, coronavirus subverts the cellular antioxidant function to its advantage to maintain an efficient replication cycle [17]. During SARS-CoV-2 infection, mitochondrial ROS are released, which in turn lead to lysosomal membrane permeabilization. The release of ROS into the cytosol triggers the activation of the NLRP3 inflammasome [18]. This complex consists of NLRP3, caspase- 1 and the bipartite adaptor protein, which is known as apoptosis-associated speck-like protein containing a caspase-recruitment domain (ASC) [19]. The NLRP3 inflammasome is involved in many inflammatory processes by activating caspase- 1 and releasing IL- $1 \beta$. The increase in IL-1 $\beta$ promotes induction of higher levels of IL-6 and Tumor Necrosis Factor (TNF)- $\alpha$ in classically activated macrophages that can result in neutrophil influx to the lung (fibrosis) and the so called "cytokine storm" in elderly patients [20].

The viral immune response is divided into two key phases: incubation (non-severe stage) and massive destruction (severe stages). In the first step, a particular adaptive immune response is crucial to reduce the incidence of the virus and halt its spread. However, if the immune response (second phase) is compromised, the virus will disperse and the 
infected tissues will be massively damaged, accompanied by triggered innate lung inflammation controlled by pro-inflammatory macrophages, granulocytes, pro-inflammatory cytokines and chemokines such as IL-6 and IP-10, macrophages inflammatory proteins (MIP), such as MIP-1 alpha, MIP-1 $\beta$, and monocyte chemotactic protein-1 (MCP-1). Inflammatory molecules attract monocytes, macrophages and $\mathrm{T}$ cells to the site of injury, inducing more inflammation and increasing pro-inflammatory cytokines, gradually destroying the lung structure and generating a cytokine storm that enters other organs, potentially damaging them [21-23]. Several studies analyzing cytokine profiles from COVID-19 patients suggested that the cytokine storm correlated directly with lung injury, multi-organ failure, and unfavorable prognosis of severe COVID-19 [24].

A diversity of clinical trials focused predominantly on antioxidants, anti-inflammatory drugs, immunomodulatory drugs and other therapies are being implemented as potential therapies for COVID-19 [25]. In the lungs of elderly COVID-19 patients there is evidence of a correlation between decreased expression of the enzyme superoxide dismutase 3 (SOD3) and disease severity [26]. Oxidation of cellular proteins, lipids, and DNA is induced by the generation of hydrogen peroxide and other ROS in situ, resulting in cellular dysfunction or death. Interestingly, the formation of severe forms of COVID-19 is less likely among infants, whose neutrophils are less receptive and failing to adhere to the redox balance without any alteration [27].

\section{Immunomodulatory Activity of Zinc}

The body comprises about 1.4-2.3 g of zinc and its contents differ considerably from one tissue to another. Around 2800 macromolecules and more than 300 enzymes require zinc in order to shape their proper structure and develop their function. The activation of enzymes involved in antioxidant defenses and with antioxidant ability has been related to the activity of free or labile types of $\mathrm{Zn}^{2+}$. It also plays a key role in preserving membrane integrity, and its deficiency impairs membrane functioning [28].

Zinc is an antioxidant and its deficiency is linked to oxidative stress and damage to DNA, lipids, and proteins and the development of diseases [29,30]. Mitochondria are semi-autonomous translation and transcription organelles. As proteins attached to the inner mitochondrial membrane require $\mathrm{Zn}^{2+}$ as a cofactor, a decrease in the concentration of $\mathrm{Zn}^{2+}$ will affect mitochondrial biogenesis [31].

Zinc itself is not redox active, so $\mathrm{Zn}^{2+}$ does not specifically associate with free radicals or with activated oxygen. Zinc interacts with sulfur in cysteines by creating a quite stable sulfur-zinc bond, which is very stable in a complex cell system and allows the metal to be either connected or disassociated. The intrinsic redox feature of thiol groups results in zinc release through oxidation reaction from metallothionine (MT) and other cysteine-zinc complex, which imparts zinc with an indirect redox activity. MT is known as the important zinc binding protein for intracellular zinc homeostasis. Zinc caused by induction of NO, $\mathrm{H}_{2} \mathrm{O}_{2}$, and oxidized antioxidants and thiol-based oxidants can be dissociated from the thiol-zinc clusters in MT. The MTs and other protein-bearing cysteines may also be used as storage carriers for cellular zinc, "redox sensors" [32].

Zinc has multiple antiviral effects on a variety of viral species, including several nidoviruses, to which SARS-CoV-2 belongs. Most of the risk groups described for COVID19 are related with zinc deficiency. Zinc-deficient populations are often at higher risk of contracting viral infections such as HIV or hepatitis C virus. Zinc modulates antiviral and antibacterial immunity, regulates the inflammatory response, possesses antiviral activity by inhibiting SARS-CoV-2 RNA polymerase, inhibits NF- $\mathrm{kB}$ signaling, and modulates regulatory T-cell functions, which can limit cytokine storm [33]. Because of its direct antiviral properties, zinc administration would presumably be beneficial for the majority of the population, especially those with suboptimal zinc status [34].

Zinc is essential to preserve natural tissue barriers such as the respiratory epithelium and to ensure a balanced function of the immune and redox systems. In the lungs, it has a protective effect as a preventive and adjuvant therapy by reducing inflammation, 
improving mucociliary clearance and preventing ventilator-induced lung injury [35]. Dinesh Jothimania et al. determined the clinical significance of serum zinc in patients and correlated it with disease severity. The study data clearly show that a significant number of patients with COVID-19 were zinc deficient. These patients developed more complications and deficiency was associated with prolonged hospital stay and increased mortality [36].

Zinc deficiency affects multiple aspects of innate and adaptive immunity [37]. In the adaptive immune system, Th1 cell differentiation and propagation are driven primarily by IL-12. Th2 cells, necessary for humoral immunity against extracellular pathogens secrete IL-4, IL-5, IL-6, IL-10, and IL-13, and are responsible for antibody responses and inhibition of various macrophage functions. The pattern of cytokines secreted by each subset acts to down-regulate the functions of the opposing subset. The physiological effects of Zinc signaling target specific molecules, influencing a wide range of cellular activities, such as proliferation, differentiation, survival, migration, and function, by selectively regulating different signaling pathways. Disruption of a Zinc signaling axis can cause immunodeficiency in the absence of redundant machinery by depressing both primary and secondary immune responses [38]. In 1997, Beck et al. studied the relationship between zinc deficiency and cytokine production by Th1 and Th2 cells, determining the proportions of CD4+ and CD8+ cells. Data were collected at the end of the zinc restriction period and after zinc repletion, indicating a reduction in Th1 cell functions, as evidenced by decreased IFN- $\gamma$, IL-2, and TNF- $\alpha$ factor, while Th 2 cell functions (IL-4, IL-6, and IL-10) were not affected by zinc deficiency. Thus, there was an imbalance between Th1 and Th2 cells due to zinc deficiency. Cytokines produced by Th1 cells are particularly sensitive to the level of zinc, as IL-2 and IFN- $\gamma$ production is decreased despite mild deficiency. Alternatively, cytokines produced by Th2 cells (IL-4, IL-5, and IL-6) are not affected by zinc deficiency. An imbalance between Th1 and Th2 cell functions is generated and induces changes in T cell subpopulations responsible for immune functions [39]. Its consequences include thymic atrophy, altered thymic hormones, lymphopenia, compromised Th1 and Th2 antibody-mediated cellular responses, as well as possible stimulation of natural killer NK cells, which result in a rapid response against the infectious load and determine the asymptomatic or mild course of the disease, as well as the duration of infection.

Zinc deficiency also plays an important role in several factors: immunosenescence in the elderly, cytokine release, DNA repair enzymes, zinc transporters, and signaling molecules, etc., forcing the immune system to adapt to the stress generated by suboptimal zinc levels [40]. Zinc deficiency is associated with lymphopenia and reduced T-lymphocytemediated immunity. In 2003, Taylor et al. elucidated an immune dysfunction by analyzing the role of Zinc in T cell signal transduction, phosphorylation steps and putative Zinc finger proteins or Zinc metalloenzymes. Elevated expression of p56lck in murine splenic T lymphocytes is induced by zinc deficiency and calorie deficiency. Zinc deficiency contributes to impaired thymocyte maturation, apoptosis, and lymphopenia [41]. Zinc deficiency directly activates endogenous endonucleases that induce DNA fragmentation and cell death, attributing this to an exchange of $\mathrm{Zn}^{2+}$ for $\mathrm{Ca}^{2+}$ and $\mathrm{Mg}^{2+}$ within cell nuclei. The zinc chelator $\mathrm{N}, \mathrm{N}, \mathrm{N}^{\prime}, \mathrm{N}^{\prime}$-tetrakis (2 pyridylmethyl) ethylenediamine (TPEN) induces translocation of cytochrome $\mathrm{c}$ from the mitochondrial intramembrane space to the cytosol in human peripheral blood T cells with subsequent activation of caspase-3, -8 , and -9. Pretreatment of T cells with caspase inhibitors prevented DNA fragmentation, so that apoptosis triggered by zinc deficiency is dependent on caspase activation. Cytochrome $c$ release and activation of downstream caspases precedes changes in mitochondrial transmembrane potential $(\Delta \Psi \mathrm{m})$. Therefore, cytoplasmic and mitochondrial events are central to this process [41].

Thymulin, a thymic hormone essential for the development and maturation of $\mathrm{T}$ cells, is involved in differentiation and in enhancing the actions of $\mathrm{T}$ and NK cells. Its activity depends on the presence of zinc in the molecule. The molecular structure of the nonapeptide is shown in Figure 2. 
A)

B)
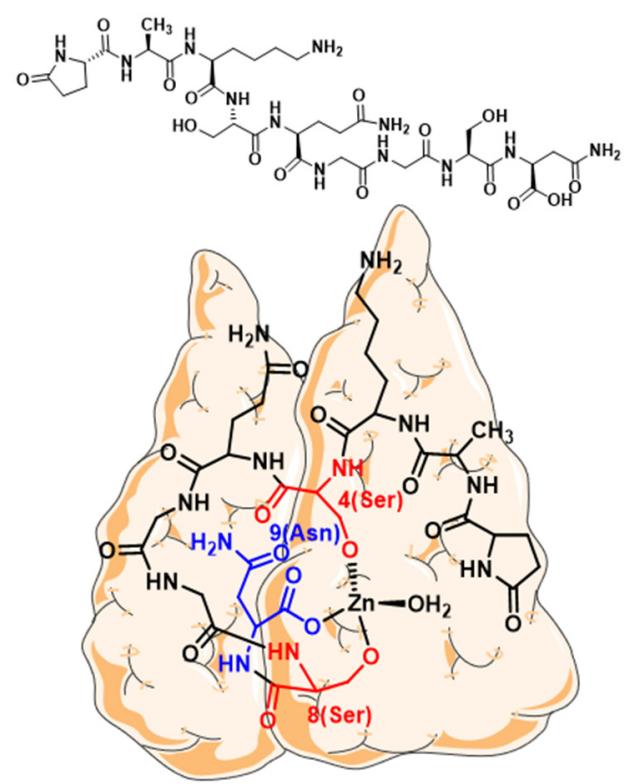

Figure 2. Molecular structure of the hormone thymulin (A) and preferred form of chelation of thymulin with Zinc (B).

A preferred form of its chelation with Zinc is shown in Figure 2. The zinc ion is in a tetrahedral environment, coordinated with a water molecule and the side-chain oxygen functions of two serinates (red) and an aspartate (blue) of the nonpeptide [42]. The level of thymulin is reduced because of mild zinc deficiency and is corrected by its supplementation. In addition, thymulin induces intra- and extrathymic T-cell differentiation. Similar changes are also observed in the lymphocyte subpopulation, correctable by zinc supplementation [43].

As the best possible treatment so far relies on the proper functioning of the individual's immune system, zinc supplementation may be beneficial for the prophylaxis and treatment of COVID-19 [44]. However, to predict the outcome of COVID-19 disease, biomarkers are needed at an early stage of infection to improve prognosis and treatment [35]. Zinc deficiency (ZD) is a common condition in older people and in people with chronic diseases [35]. Serum zinc content (SZC) influences the progression of COVID-19 disease and could therefore represent a useful biomarker [45]. Tapazoglou et al. studied NK cell activity in adults with sickle cell disease and in normal volunteers with zinc deficiency due to dietary restrictions [46]. NK activity was significantly lower in patients with sickle cell disease and zinc deficiency $\left(5.1+/-2.9\right.$ lytic units $/ 10^{6}$ cells $)$ than in controls $(11.7+/-$ 5.0 lytic units $/ 10^{6}$ cells). In volunteers, $\mathrm{NK}$ activity decreased during zinc restriction and returned to baseline levels with zinc repletion. Muzzioli et al. evaluated the effect of zinc on the kinetics of CD34+ progenitor cells towards NK cells at young and old ages [47]. CD34+ cells progressively lost CD34 antigen, with faster kinetics in older than in younger donors. Zinc supplementation greatly increased the number of NK cells and their cytotoxic activity at both young and old ages. In zinc-supplemented cultures, a 3.6-fold and 4.1-fold increases in the expression of the transcription factor GATA-3 were observed in young and old donors, respectively. Zinc influences proliferation and differentiation of CD34+ progenitors at both young and old ages.

Zinc homeostasis affects the maturation of dendritic cells (DC), which are necessary to shape T-cell responses. The mechanism by which zinc regulates DCs remains largely unknown. The effect of Zinc on DC phenotype and the generation of regulatory T cells (Tregs) is investigated in a model of Histoplasma capsulatum fungal infection. Zinc shapes the tolerogenic potential of DCs in vitro and in vivo and promotes Tregs during fungal infection [48]. In 2020, Jothimania et al. determined the clinical significance of serum zinc in patients and correlated it with disease severity. The study data clearly show that a 
significant number of patients with COVID-19 were zinc deficient. They developed more complications and deficiency was associated with prolonged hospital stay and increased mortality [36].

\section{Glutathione as Antioxidant Defense and Immune Modulator}

Glutathione is a glycine, cysteine, and glutamic acid tripeptide that is active in important aspects of cellular homeostasis. Glutathione plays many important roles in physiological processes which can affect disease pathophysiology including preservation of redox balance, reduction of oxidative stress, enhancement of mitochondrial detoxification, and control of immune system activity [49]. Glutathione is the most important antioxidant in the body, particularly in the lungs. By exposure to oxidative sources in the blood, the lungs obtain all cardiac debit, and are subjected to oxidative stress by cumulative ROS [50]. In metabolism, the multiple functions of glutathione are significant to a large body of evidence showing that glutathione status in different chronic, age-related diseases may be an essential biomarker and treatment target [51]. Glutathione is present in the reduced (GSH) and oxidized (GSSG) forms. GSH is the primary reduction agent in most cells where it is active at millimolar concentrations. The intracellular redox state, and in particular the GSH stage, can modulate the immune system by operating at different levels of the immune regulatory network, including cellular and humoral reaction, proliferation, and cytokine synthesis of immune cells and by means of different mechanisms of action [52]. Therefore, GSH can be a highly useful method in the treatment of several pathogens [53].

Several viral infections, induced by both DNA and RNA viruses, are characterized by modification of the intracellular redox balance, sometimes correlated with GSH depletion, which differs in severity, length, and process of induction depending on the form of virus and the host cell infected [53]. In general, rapid reductions in GSH levels have been reported following infection with viruses that cause immediate cytopathic results in epithelial cells [54]. The SARS-CoV-2 virus can lower the function of the renin-angiotensin system in the lungs through the down-regulation of the cell surface ACE2 receptor, followed by free radical mediated inflammation, and unveils the protective function of GSH [55]. In the early stage of infection, host cell membrane disturbance triggers a decrease in intracellular $\mathrm{pH}$ and GSH efflux, allowing the virus cycle to begin. In the late stages of infection, the depletion of GSH is attributed to its usage in the development of mixed disulfides with viral proteins and the selective integration of cysteine into viral proteins. Low body GSH levels may be one of the main causes of the excessive inflammatory reaction, and that boosting body GSH may decrease the number of symptomatic patients [55]. Indeed, GSH has been suggested to inhibit the reproduction of many viruses that have either DNA or RNA genomes.

To understand the antiviral function of GSH, different mechanisms of action have been suggested [55]. In antigen presenting cells (APC), decreased glutathione levels affect the synthesis and presentation of antigen as well as the differentiation of T cells into Th1 or Th2 phenotypes. The differentiation of naive CD4+ T cells to Th1 cells is stimulated by IL-12 and IL-27, whereas IL-10 favors the production of Th2 T cells. Decreased levels of GSH in APCs hinder the capacity of macrophages to process antigens and secrete IL-12 contributing to polarization of Th2 response patterns; on the contrary, elevated levels of GSH promote the Th1 response. Significantly, the amounts of IL-12 secreted by macrophages can be modulated by adjusting the intracellular GSH/GSSG balance. GSH can affect the replication and/or survival of viruses and bacteria directly [53]. Consequently, various GSH replenishing molecules can be used as immunomodulators to stimulate the immune response of Th1 by IL-12 synthesis and as antimicrobials to prevent the reproduction of several pathogens. In fact, the combination of these two effects is a creative and successful technique to tackle a variety of infections. Pro-GSH molecules have also been suggested to improve the secretion of IL-12 and IFN-gamma in diabetics to partly overcome the immunological modifications correlated with the condition and their possible role in raising the sensitivity of these subjects to intracellular bacterial infections [53]. 
Based on the ability of glutathione GSH to inhibit viral replication and IL-6 in patients with human immunodeficiency virus HIV and tuberculosis TB, as well as its beneficial effects in other lung diseases, it is inferred that the use of GSH is beneficial in patients with COVID-19 $[55,56]$. The enhanced vulnerability of the aged, diabetics, and obese to COVID-19 is partially attributed to their decreased capacity to sustain elevated GSH and redox status during viral infection. Glutathione (GSH) levels are critical to extinguish exacerbated inflammation [55]. High levels of reduced glutathione in antigen-presenting cells are important for mounting an adaptive immune response to viral infections and for preventing inflammatory cytokine reactions. GSH promotes a robust immune response to viral infections, enhancing Th1 response without over-stimulating the inflammatory response of Th2 [53].

Optimizing glutathione levels has been suggested as a method to improve wellbeing and avoid disease. Boosting GSH may be used to improve the immune response of Th1 in older people whose immune systems are weakened and unable to effectively resist infectious diseases and respond to vaccine programs. Glutathione-boosting supplements like N-Acetyl Cysteine (NAC), Alpha Lipoic Acid (ALA), and Liposomal Reduced Glutathione have beneficial effects in the battle against viral redox status and immune response. NAC has antioxidant, anti-inflammatory, and immunomodulatory characteristics that may be beneficial in the treatment and prevention of SARS-Cov-2 [57]. Restoration of glutathione levels in patients with COVID-19 would be a promising approach for the treatment of the new coronavirus. Long-term oral administration of $\mathrm{N}$-acetylcysteine has already proven to be an effective preventive measure against respiratory viral infections [58]. Although one of the safest pathways to fortifying an intrinsic resistance against oxidative stress and raising glutathione levels will best be applied via the richness and pleiotropism of several phytonutrients. Dietary treatments, including amino acids, proteins, minerals, phytochemicals, and diets, can have major impacts on circulating glutathione [59].

\section{Warburg Effect Due to COVID-19 and its Relationship with Glutathione Depletion}

Energy storage in mitochondria takes place in the form of adenosine triphosphate (ATP), in a process called oxidative phosphorylation (OXPHOS) which involves the transport of $\mathrm{H}^{+}$protons across the mitochondrial inner membrane to the intermembrane space. From here, protons return to the matrix during the oxidative phosphorylation reaction, so there is a reducing environment inside. The reaction to produce ATP from ADP have a negative Gibbs free energy, $\Delta G \leq 0$, and occurs spontaneously (Figure 3).

The Warburg effect is characterized by irreversible damage of mitochondrial oxidative phosphorylation and an increase in the rate of glycolysis. Molecular metabolic pathways switch from oxidative phosphorylation to aerobic glycolysis, due to changes in glucose degradation mechanisms, a process known as "Warburg reprogramming" of cells. In the Warburg effect, most cancer cells produce energy mainly in the cytosol, by a route of aerobic glycolysis, followed by a process of lactic fermentation. Neoplastic cells have glucose consumption rates about 200 times higher than normal cells, and this occurs even with full oxygen supply.

Icard et al., 2021, maintain that replication of many viruses, including MERS-CoV, is supported by aerobic glycolysis, and therefore hypothesize that SARS-CoV-2 replication in host cells (especially those of the respiratory tract) depends on altered glucose metabolism. This metabolism is like the Warburg effect in cancer. Once induced by hypoxia, the Warburg effect is activated in pulmonary endothelial cells, particularly in the presence of atherosclerosis, which promotes vasoconstriction and micro-thrombosis. Aerobic glycolysis also supports the activation of pro-inflammatory cells such as neutrophils and M1 macrophages [60]. Hypoxia accompanies all stages of the disease, is a primary pathophysiological feature, and is the main cause of mortality in severe COVID-19 patients. Its pathogenic features act at systemic, organ, and cellular levels, and its consequences can have aggregate effects on each other $[61,62]$. 


\section{$\mathrm{ADP}+\mathrm{Pi}+3 \mathrm{H}^{+}$out $\longrightarrow \mathrm{ATP}+3 \mathrm{H}^{+}$in $\quad \Delta \mathrm{G}^{\circ}=-1,7 \mathrm{Kcal} / \mathrm{mol}$}
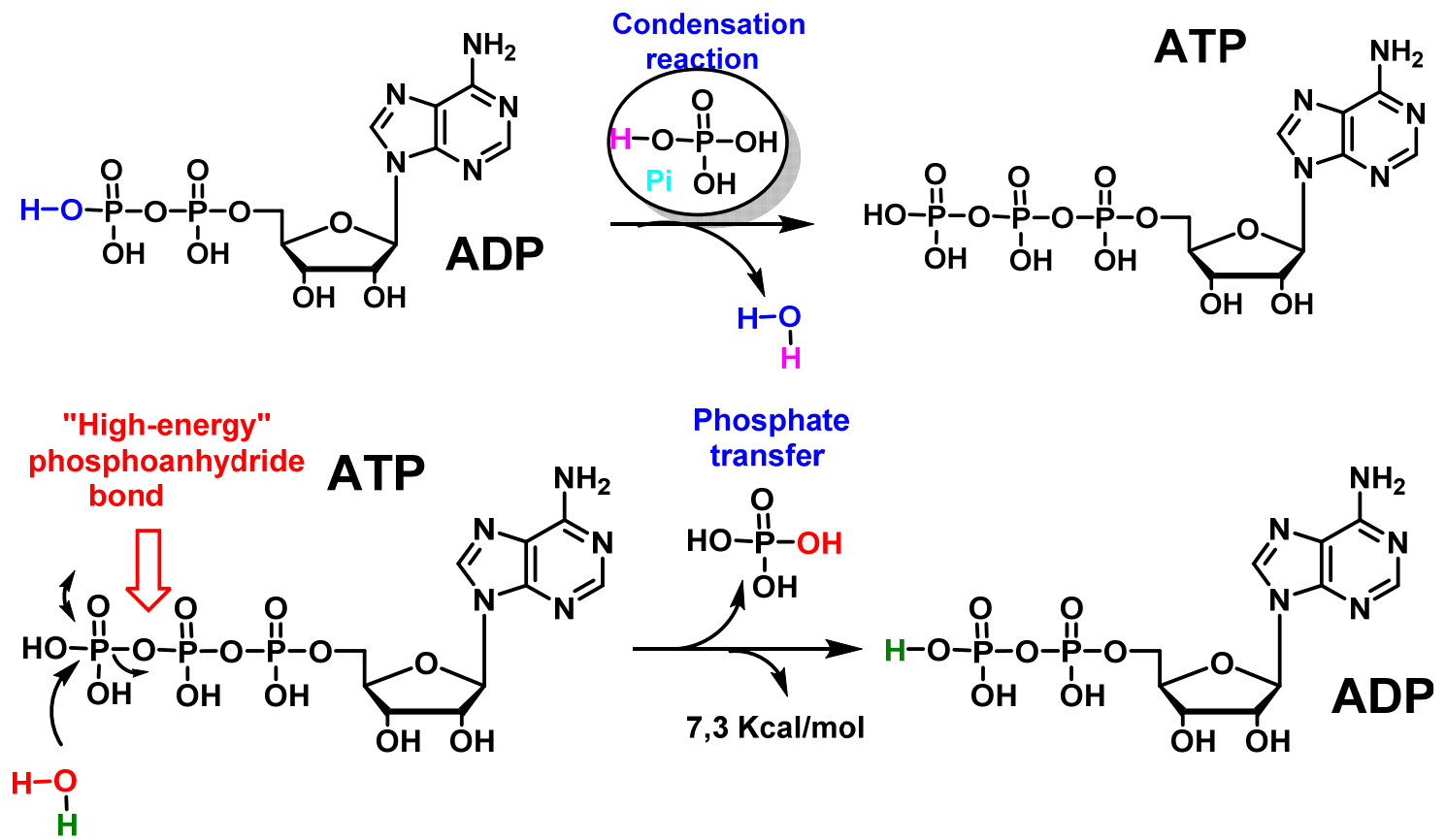

Figure 3. ADP conversion to adenosine triphosphate (ATP) by condensation reaction involves the transport of $\mathrm{H}^{+}$protons across the mitochondrial inner membrane to the intermembrane space, whereas the reaction to produce ATP from ADP have a negative Gibbs free energy, $\Delta \mathrm{G} \leq 0$, and occurs spontaneously.

Thaker et al., 2019, describe the current understanding of how different viruses rewire host cell metabolism to achieve optimal viral replication. Both DNA and RNA viruses reprogram several aspects of central host metabolism, such as increased glycolysis, elevated pentose phosphate activity to support nucleotide generation, amino acid generation, and lipid synthesis [63]. Laviada-Molina et al., 2020, hypothesize that after SARS-CoV-2 infects human cells, it utilizes excess glucose for rapid viral replication from the hexosamine biosynthetic pathway (HBP), sequestering substrates from the metabolic environment. Overexpression of IRF5 interferon and inflammatory genes are induced, as well as endoplasmic reticulum (ER) stress and a deregulated cytokine profile. This leads to an increased risk of vascular hyperpermeability, multi-organ failure, and hyperinflammation [64].

During ex-novo synthesis of glutathione, glutamate, and cysteine are combined by the enzyme glutamate-cysteine ligase (GCL) to form glutamyl-cysteine, which is then combined with glycine by glutathione synthase (GS). GSH is synthesized in a 2-step reaction, requiring two molecules of adenosine triphosphate ATP, which are transformed into ADP and Pi. GSH is a reductant in cellular redox reactions, forming glutathione disulfide (GSSG), which can be reduced again to regenerate the GSH.

As can be seen in Figure 4, one molecule of ATP is consumed in each step of GSH synthesis. If the hypothesis that the pathophysiological response in severe patients induces the activation of the Warburg effect in lung cells is considered true, then there is automatically a quantitative decrease in oxidative phosphorylation in the mitochondria of these cells, reducing ATP synthesis from ADP within the mitochondrial matrix. Dysfunction in ATP production means that it is not available in sufficient quantity to be consumed in the two steps of the ex-novo reduced glutathione synthesis, leading to significant glutathione depletion and progressive worsening of the patient. 


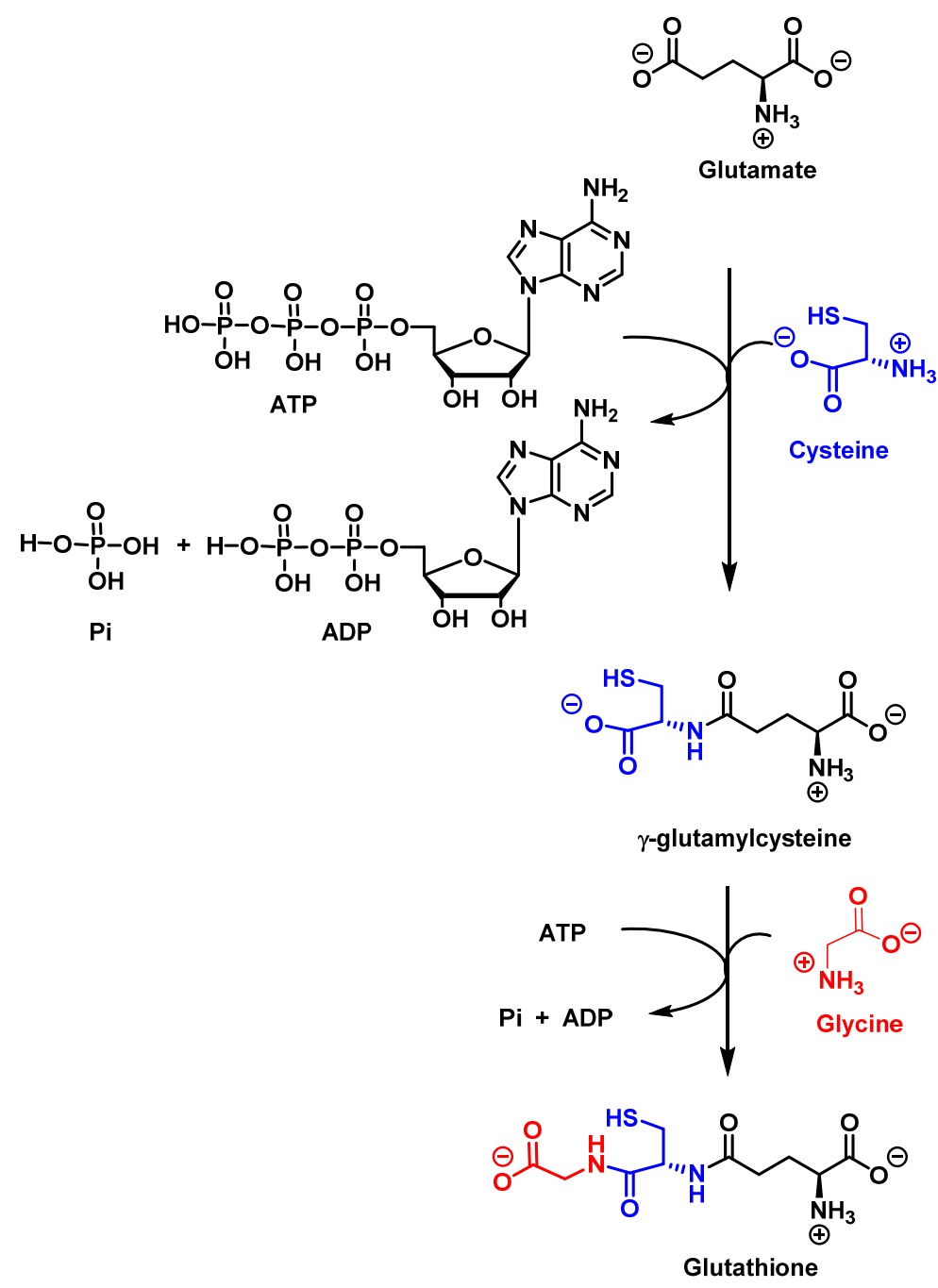

Figure 4. Ex-novo synthesis of glutathione. Glutamate and cysteine are combined by the enzyme glutamate-cysteine ligase (GCL) to form glutamyl-cysteine, which is then combined with glycine by glutathione synthase (GS). Glutathione (GSH) is synthesized in a 2-step reaction, requiring two molecules of ATP, which are transformed into ADP and Pi. One molecule of ATP is consumed in each step of GSH synthesis.

\section{Polyphenols as Natural Products of Nutritional Interest}

Polyphenols are the largest class of plant-based bioactive compounds, developed as secondary metabolites with protective functions against ultraviolet radiation, pathogen hostility, and defense against oxidative stress $[65,66]$. The word polyphenol structurally relates to the inclusion of hydroxy groups of one or more phenolic rings. On these bases, polyphenols can be categorized as flavonoids (including anthocyanins, flavanes, flavonols, isoflavones, and flavan-3ols), phenolic acids, polyphenolic amides, and other polyphenol compounds. Polyphenols have been widely researched for their various health benefits, in particular their good antioxidant and anti-inflammatory properties [65,67-69]. With their beneficial effects on various chronic diseases and on bacterial and viral infections, the properties of polyphenols can be a quick, healthy and cost-effective solution in several cellular and molecular pathways, contributing to a better immunity of the body [69].

Many naturally occurring polyphenols are inexpensive to manufacture and have low potential for production of toxicity, rendering these compounds ideal candidates for preventative therapy to decrease viral infectivity and inflammation [70]. Polyphenols tend to share a variety of unique chemical properties, including the presence of a phenolic ring with hydroxyl groups (Figure 5). At the molecular level, polyphenols are promising as 
inhibitors of viral proteases involved in viral replication due to their general affinity to hydrogen bonding proteins and their low probability of toxic effects. Thus, it may be speculated that while various forms of polyphenols can share the same anti-viral activity, they could work by different mechanisms.<smiles>O=c1cc(-c2ccccc2)oc2cc(O)c(O)c(O)c12</smiles>

Baicalein is a flavone<smiles>O=c1c(O)c(-c2ccc(O)c(O)c2)c2oc3cc(O)cc(O)c3oc1=2</smiles>

Quercetin is a flavonol<smiles>Oc1cc(O)c2c(c1)Oc1cc(-c3ccc(O)c(O)c3)ccc1O2</smiles>

Luteolin is a flavone

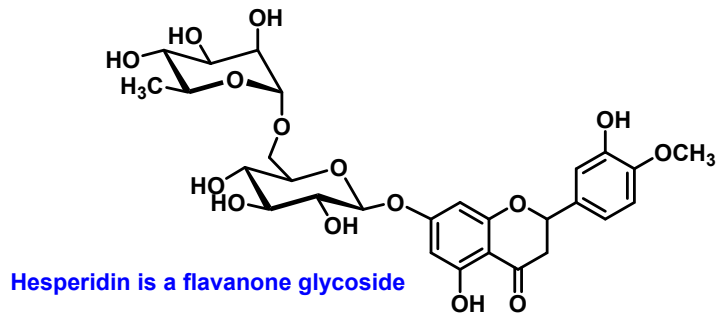<smiles>Oc1cc(O)c2c(c1)O[C@H](c1cc(O)c(O)c(O)c1)C(O)C2</smiles>

Gallocatechol or Gallocatechin is a flavan-3-ol<smiles>O=C(O[C@H]1Cc2c(O)cc(O)cc2O[C@H]1c1cc(O)c(O)c(O)c1)c1cc(O)c(O)c(O)c1</smiles>

Epigallocatechin-3-gallate, is the ester of epigallocatechin and gallic acid

Figure 5. Examples of polyphenols. Polyphenols can be categorized as flavonoids (including anthocyanins, flavanes, flavonols, isoflavones, and flavan-3ols). Polyphenols tend to share a variety of unique chemical properties, including the presence of a phenolic ring with hydroxyl groups.

Polyphenols have been documented to be successful in alleviating the pathological consequences of viral infection at respiratory stage, decreasing the amount of pro-inflammatory interleukins, like IL-1 $\beta$, IL-6, and IL-8 [71]. The antiviral activity of polyphenols is attributed to interactions between phenyl rings and viral proteins and/or RNA, or to their potential to interfere with the defense of the host cell by controlling the signaling of Mitogen activated protein kinase (MAPK). Several in silico and in vitro studies have shown that polyphenols can interfere with various stages of the coronavirus entry and replication cycle [70]. Quercetin, baicalin, luteolin, hesperidin, gallocatechin, epigallocatechin gallate, and other metabolites present in plant tissues, with antioxidant and anti-inflammatory functions, can inhibit key proteins involved in the infectious cycle of coronaviruses, such as PLpro, 3CLpro, NTPase/helicase, and so on. Their pleiotropic activities and lack of systemic toxicity allow their properties to be tested to enrich the arsenal of drugs against coronavirus infections [72]. Quercetin and luteolin reduce IL-6 expression in mast cells and may be a safer alternative to corticosteroid treatment [73].

The ingestion of polyphenols, recognized as powerful antioxidants capable of stopping virus-driven ROS development and shielding host cells from oxidative stress and the vicious inflammatory cycle, will stop certain anomalies. Polyphenols may also be a successful method to avoid the harmful consequences of SARS-CoV-2, thus ameliorating the clinical trajectory of COVID-19 by improving the antioxidant potential and scavenging ROS [70]. Lutein is a natural yellow dye present in many plants, including broccoli, pepper, thyme, celery, carrots, olives, mint, rosemary, oregano, rosemary, celery, sage, navel 
oranges, and dandelion. Luteolin inhibited lipopolysaccharide (LPS)-elicited inflammatory events in mouse alveolar macrophages including cyclooxygenase-2 (COX2), TNF- $\alpha$, IL-6, inducible nitric oxide synthase (iNOS) and ROS development was prevented by repressing NF- $\mathrm{kB}$ and AP-1 activation pathways, indicating a potential therapeutic use of luteolin for treating lung inflammatory disorders.

Naringenin exists naturally in different citrus fruits, bergamot, tomato products, grapefruit, sour orange, cherries, and cocoa and can be present in certain herbs such as oregano and water mint. Naringenin inhibits the phosphorylation of MAPKs by reducing NF- $\mathrm{KB}$ and AP-1 translocation and DNA binding, which limits the development of pro-inflammatory cytokines such as IL-33, TNF- $\alpha$, IL-1 $\beta$, and IL-6 [74]. Naringenin has been reported to have suppressed respiratory overexpression and eosinophilic airway inflammation in asthma and thus reduced acute neutrophilic airway inflammation by blocking the NF- $\mathrm{KB}$ pathway [75]. Naringenin may be used against pneumonia associated with the spread of COVID-19 owing to its good anti-inflammatory and antioxidant activity.

Notably, because of its bonding ability to viral enveloped lipid or sugar moieties, the antiviral impact of polyphenols is not greatly impaired by viral mutations. These remarkable characteristics of polyphenols as natural, economical, easy, and environmentally sustainable compounds highlights the current state of awareness of the most effective polyphenol compounds [68], their relative value, and their general properties in human health, concentrating mainly on their antiviral function, and their role in the enhancement of the immune system.

\section{Zinc, Glutathione and Polyphenols in the Immune Response against SARS-CoV-2}

The emergence of a potentially fatal disease, COVID-19, has led hospitals around the world to reach a level of overcrowding unseen in recent medical history.

The disrupted redox homeostasis responsible for reactive oxygen species (ROS) accumulation tends to be a common denominator in all conditions associated with COVID19 [76]. SARS-CoV-2 infection triggers massive production of ROS [77], and excessive oxidative damage is responsible for secretion of the cytokine storm, impaired immunity, and the emergence of pulmonary dysfunction (Figure 6). SARS-CoVs activate oxidative stress pathways that lead to the pathogenesis and development of respiratory diseases [78,79]. As a result of enhanced inflammatory cell recruitment at the site of viral infection, abundant ROS production is coupled with innate immunity and NF- $\mathrm{kB}$ activation regulated by SARS-CoV 3CLpro, contributing to an exaggerated proinflammatory host response [80].

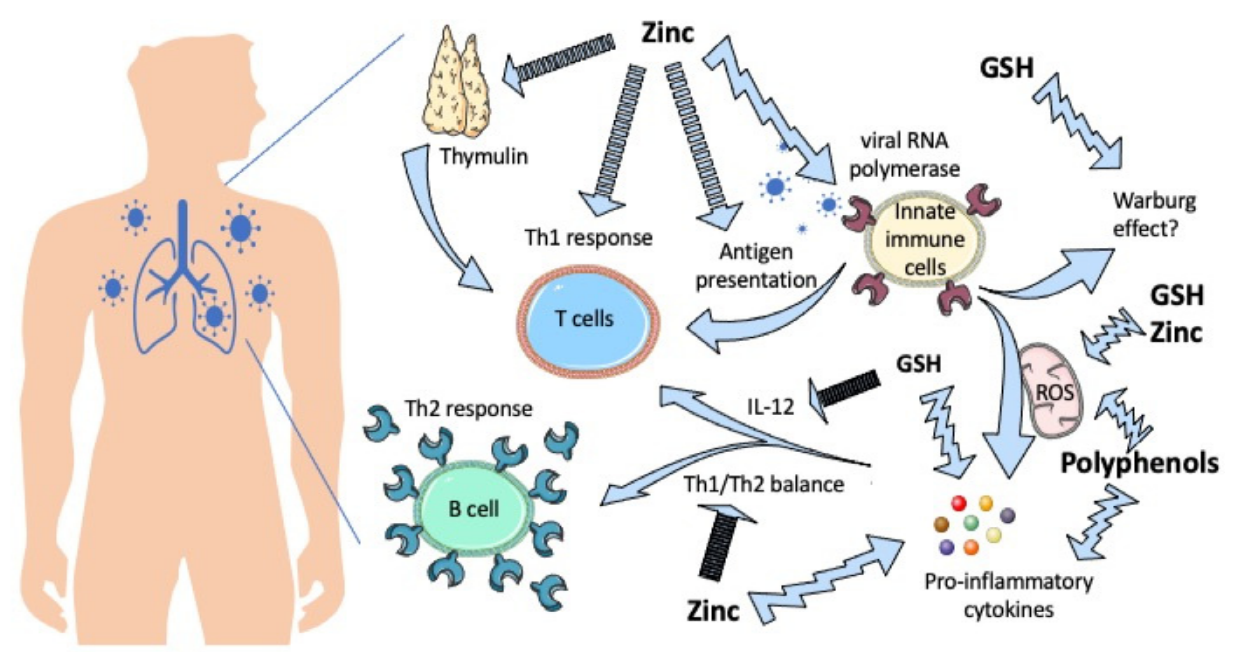

Figure 6. Different mechanisms of interaction of the three antioxidants of nutritional value: zinc, GSH and polyphenols, in the immune response against SARS-CoV-2 that occurs primary in the lungs. The negative impact is depicted with zig zagged arrows, whereas positive impact is depicted with discontinued arrows. 
Antioxidants such as zinc, glutathione, and polyphenols can become promising tools for reducing hyperactivation of cytokines such as TNF alpha, IL-1 $\beta$, IL-6, and IL-8 for the treatment of COVID-19 and for the prevention of age-related diseases and the care of patients suffering from this viral infection (Table 1).

Table 1. Impact of the antioxidants zinc, glutathione and polyphenols in the COVID-19 immune response.

\begin{tabular}{|c|c|c|}
\hline Antioxidant & Role in COVID-Immune Response & Reference \\
\hline \multirow{8}{*}{ Zinc } & Inhibition of viral RNA polymerase & \multirow{8}{*}[81-83]{} \\
\hline & Development of neutrophils and natural killer cells & \\
\hline & Increases cytotoxicity of NK cells & \\
\hline & Restores thymulin activity & \\
\hline & Increases numbers of cytotoxic $\mathrm{T}$ cells & \\
\hline & Reduces numbers of activated T helper cells & \\
\hline & Improves cell-mediated immunity, decreases oxidative & \\
\hline & stress, and generation of chronic inflammatory cytokines & \\
\hline GSH & Slow the recovery time of patients & {$[58,84]$} \\
\hline \multirow{3}{*}{ Polyphenols } & Balance the Th1/Th2 cytokine response pattern & \multirow{3}{*}[85]{} \\
\hline & Reducing inflammation & \\
\hline & Modifying senescence markers & \\
\hline
\end{tabular}

Further research is needed and clinical trials are currently under development to investigate how these antioxidants help minimize the distress and mortality associated with SARS-CoV-2 infection. We expect that our research provides a novel perspective that contribute to the design of clinical or nutritional targets for the prevention of this pandemic.

Author Contributions: Conceptualization, C.A.-J. and E.P.-L.; investigation, C.A.-J., J.M.P.d.l.L. and E.P.-L.; writing-original draft preparation, figures, review and editing, J.M.P.d.l.L. and F.J.P. All authors have read and agreed to the published version of the manuscript.

Funding: This work was supported by grants from the Spanish Ministry of Economy and Competitiveness (Grant PID2019-105838RB-C31).

Institutional Review Board Statement: Not applicable.

Informed Consent Statement: Not applicable.

Conflicts of Interest: The authors declare no conflict of interest. The funders had no role in the design of the study; in the collection, analyses, or interpretation of data; in the writing of the manuscript, or in the decision to publish the results.

\section{References}

1. Neha, K.; Haider, M.R.; Pathak, A.; Yar, M.S. Medicinal prospects of antioxidants: A review. Eur. J. Med. Chem. 2019, 178, 687-704. [CrossRef]

2. Mailloux, R.J. An Update on Mitochondrial Reactive Oxygen Species Production. Antioxidants 2020, 9, 472. [CrossRef]

3. Cano Sanchez, M.; Lancel, S.; Boulanger, E.; Neviere, R. Targeting Oxidative Stress and Mitochondrial Dysfunction in the Treatment of Impaired Wound Healing: A Systematic Review. Antioxidants 2018, 7, 98. [CrossRef]

4. Hourieh, A. A Review on Free Radicals and Antioxidants. Infect. Disord. Drug Targets 2020, 20, 16-26. [CrossRef]

5. Srivastava, S. The Mitochondrial Basis of Aging and Age-Related Disorders. Genes 2017, 8, 398. [CrossRef]

6. DeBalsi, K.L.; Hoff, K.E.; Copeland, W.C. Role of the mitochondrial DNA replication machinery in mitochondrial DNA mutagenesis, aging and age-related diseases. Ageing Res. Rev. 2017, 33, 89-104. [CrossRef]

7. Mrityunjaya, M.; Pavithra, V.; Neelam, R.; Janhavi, P.; Halami, P.M.; Ravindra, P.V. Immune-Boosting, Antioxidant and Antiinflammatory Food Supplements Targeting Pathogenesis of COVID-19. Front. Immunol. 2020, 11, 570122. [CrossRef]

8. Market, M.; Angka, L.; Martel, A.B.; Bastin, D.; Olanubi, O.; Tennakoon, G.; Boucher, D.M.; Ng, J.; Ardolino, M.; Auer, R.C. Flattening the COVID-19 Curve with Natural Killer Cell Based Immunotherapies. Front. Immunol. 2020, 11, 1512. [CrossRef] [PubMed]

9. Hong Liu, S.C.; Min, L.; Hao, N.; Hongyun, L. Comorbid Chronic Diseases are Strongly Correlated with Disease Severity among COVID-19 Patients: A Systematic Review and Meta-Analysis. Aging Dis. 2020, 11, 668-678. [CrossRef]

10. Nadhan, R.; Patra, D.; Krishnan, N.; Rajan, A.; Gopala, S.; Ravi, D.; Srinivas, P. Perspectives on mechanistic implications of ROS inducers for targeting viral infections. Eur. J. Pharmacol. 2021, 890, 173621. [CrossRef] 
11. Li, Z.; Xu, X.; Leng, X.; He, M.; Wang, J.; Cheng, S.; Wu, H. Roles of reactive oxygen species in cell signaling pathways and immune responses to viral infections. Arch. Virol. 2017, 162, 603-610. [CrossRef] [PubMed]

12. Diniz, L.R.L.; Bezerra Filho, C.d.S.M.; Fielding, B.C.; de Sousa, D.P. Natural Antioxidants: A Review of Studies on Human and Animal Coronavirus. Oxidative Med. Cell. Longev. 2020, 2020, 3173281. [CrossRef]

13. Zhang, Z.; Rong, L.; Li, Y.-P. Flaviviridae Viruses and Oxidative Stress: Implications for Viral Pathogenesis. Oxidative Med. Cell. Longev. 2019, 2019, 1409582. [CrossRef]

14. Agod, Z.; Fekete, T.; Budai, M.M.; Varga, A.; Szabo, A.; Moon, H.; Boldogh, I.; Biro, T.; Lanyi, A.; Bacsi, A.; et al. Regulation of type I interferon responses by mitochondria-derived reactive oxygen species in plasmacytoid dendritic cells. Redox Biol. 2017, 13, 633-645. [CrossRef]

15. Astuti, I. Severe Acute Respiratory Syndrome Coronavirus 2 (SARS-CoV-2): An overview of viral structure and host response. Diabetes Metab. Syndr. Clin. Res. Rev. 2020, 14, 407-412. [CrossRef]

16. Frizzelli, A.; Tuttolomondo, D.; Aiello, M.; Majori, M.; Bertorelli, G.; Chetta, A. What happens to people's lungs when they get coronavirus disease 2019? Acta Bio Med. Atenei Parm. 2020, 91, 146-149. [CrossRef]

17. Akki, R.; Fath, N.; Mohti, H. COVID-19: Oxidative Preconditioning as a Potential Therapeutic Approach. ACS Chem. Neurosci. 2020, 11, 3732-3740. [CrossRef]

18. Heid, M.E.; Keyel, P.A.; Kamga, C.; Shiva, S.; Watkins, S.C.; Salter, R.D. Mitochondrial Reactive Oxygen Species Induces NLRP3-Dependent Lysosomal Damage and Inflammasome Activation. J. Immunol. 2013, 191, 5230-5238. [CrossRef]

19. Kelley, N.; Jeltema, D.; Duan, Y.; He, Y. The NLRP3 Inflammasome: An Overview of Mechanisms of Activation and Regulation. Int. J. Mol. Sci. 2019, 20, 3328. [CrossRef]

20. Pedro C Lara, D.M.; Macías-Verde, J.B.-B. Age-induced NLRP3 Inflammasome Over-activation Increases Lethality of SARS-CoV-2 Pneumonia in Elderly Patients. Aging Dis. 2020, 11, 756-762. [CrossRef]

21. Gao, Y.-M.; Xu, G.; Wang, B.; Liu, B.-C. Cytokine storm syndrome in coronavirus disease 2019: A narrative review. J. Intern. Med. 2021, 289, 147-161. [CrossRef]

22. Shi, Y.; Wang, Y.; Shao, C.; Huang, J.; Gan, J.; Huang, X.; Bucci, E.; Piacentini, M.; Ippolito, G.; Melino, G. COVID-19 infection: The perspectives on immune responses. Cell Death Differ. 2020, 27, 1451-1454. [CrossRef]

23. Snehal, B.; Anurag, M.; Shruti, C.; Aanchal, N. The Cytokine Storm in COVID-19. Available online: https://www.praxisug.com/ index.php/Praxis/article/view/100 (accessed on 12 February 2021).

24. Ragab, D.; Salah Eldin, H.; Taeimah, M.; Khattab, R.; Salem, R. The COVID-19 Cytokine Storm; What We Know So Far. Front. Immunol. 2020, 11, 1446. [CrossRef]

25. Zhu, R.-F.; Gao, Y.-L.; Robert, S.-H.; Gao, J.-P.; Yang, S.-G.; Zhu, C.-T. Systematic review of the registered clinical trials for coronavirus disease 2019 (COVID-19). J. Transl. Med. 2020, 18, 274. [CrossRef]

26. Abouhashem, A.S.; Singh, K.; Azzazy, H.M.E.; Sen, C.K. Is Low Alveolar Type II Cell SOD3 in the Lungs of Elderly Linked to the Observed Severity of COVID-19? Antioxid. Redox Signal. 2020, 33, 59-65. [CrossRef] [PubMed]

27. Laforge, M.; Elbim, C.; Frère, C.; Hémadi, M.; Massaad, C.; Nuss, P.; Benoliel, J.-J.; Becker, C. Tissue damage from neutrophilinduced oxidative stress in COVID-19. Nat. Rev. Immunol. 2020, 20, 515-516. [CrossRef]

28. Pasternak, C.A. A novel role of $\mathrm{Ca} 2+$ and Zn2+: Protection of cells against membrane damage. Biosci. Rep. 1988, 8, 579-583. [CrossRef]

29. Prasad, A.S. Zinc is an Antioxidant and Anti-Inflammatory Agent: Its Role in Human Health. Front. Nutr. 2014, 1, 14. [CrossRef] [PubMed]

30. Prasad, A.S. Discovery of Human Zinc Deficiency: Its Impact on Human Health and Disease. Adv. Nutr. 2013, 4, 176-190. [CrossRef] [PubMed]

31. Lee, S.R. Critical Role of Zinc as Either an Antioxidant or a Prooxidant in Cellular Systems. Oxidative Med. Cell. Longev. 2018, 2018, 9156285. [CrossRef]

32. Rahman, M.T.; Karim, M.M. Metallothionein: A Potential Link in the Regulation of Zinc in Nutritional Immunity. Biol. Trace Elem. Res. 2018, 182, 1-13. [CrossRef]

33. de Almeida Brasiel, P.G. The key role of zinc in elderly immunity: A possible approach in the COVID-19 crisis. Clin. Nutr. Espen 2020, 38, 65-66. [CrossRef]

34. Wessels, I.; Rolles, B.; Rink, L. The Potential Impact of Zinc Supplementation on COVID-19 Pathogenesis. Front. Immunol. 2020, 11, 1712. [CrossRef]

35. Skalny, A.V.; Rink, L.; Ajsuvakova, O.P.; Aschner, M.; Gritsenko, V.A.; Alekseenko, S.I.; Svistunov, A.A.; Petrakis, D.; Spandidos, D.A.; Aaseth, J.; et al. Zinc and respiratory tract infections: Perspectives for CoviD'19 (Review). Int. J. Mol. Med. 2020, 46, 17-26. [CrossRef]

36. Jothimani, D.; Kailasam, E.; Danielraj, S.; Nallathambi, B.; Ramachandran, H.; Sekar, P.; Manoharan, S.; Ramani, V.; Narasimhan, G.; Kaliamoorthy, I.; et al. COVID-19: Poor outcomes in patients with zinc deficiency. Int. J. Infect. Dis. 2020, 100, 343-349. [CrossRef]

37. Chasapis, C.T.; Ntoupa, P.S.A.; Spiliopoulou, C.A.; Stefanidou, M.E. Recent aspects of the effects of zinc on human health. Arch. Toxicol. 2020, 94, 1443-1460. [CrossRef]

38. Hojyo, S.; Fukada, T. Roles of Zinc Signaling in the Immune System. J. Immunol. Res. 2016, 2016, 6762343. [CrossRef] 
39. Prasad, A.S.; Beck, F.W.J.; Grabowski, S.M.; Kaplan, J.; Mathog, R.H. Zinc deficiency: Changes in cytokine production and T-cell subpopulations in patients with head and neck cancer and in noncancer subjects. Proc. Assoc. Am. Physicians 1997, $109,68-77$.

40. Nriagu, J. Zinc deficiency in human health. In Encyclopedia of Environmental Health; Elsevier: Amsterdam, The Netherlands, 2019; pp. 489-499. [CrossRef]

41. Taylor, C.G.; Giesbrecht, J.A.C. Dietary zinc deficiency and expression of T lymphocyte signal transduction proteins. Can. J. Physiol. Pharmacol. 2000, 78, 823-828. [CrossRef]

42. Dardenne, M.; Pleau, J.-M. Interactions Between Zinc and Thymulin. Metal. Based Drugs 1994, 1, 204305. [CrossRef]

43. Prasad, A.S.; Meftah, S.; Abdallah, J.; Kaplan, J.; Brewer, G.J.; Bach, J.F.; Dardenne, M. Serum thymulin in human zinc deficiency. J. Clin. Investig. 1988, 82, 1202-1210. [CrossRef]

44. Kumar, A.; Kubota, Y.; Chernov, M.; Kasuya, H. Potential role of zinc supplementation in prophylaxis and treatment of COVID-19. Med. Hypotheses 2020, 144, 109848. [CrossRef]

45. Vogel-González, M.; Talló-Parra, M.; Herrera-Fernández, V.; Pérez-Vilaró, G.; Chillón, M.; Nogués, X.; Gómez-Zorrilla, S.; López-Montesinos, I.; Villar, J.; Sorli-Redó, M.L.; et al. Low zinc levels at clinical admission associates with poor outcomes in COVID-19. medRxiv 2020. [CrossRef]

46. Tapazoglou, E.; Prasad, A.S.; Hill, G.; Brewer, G.J.; Kaplan, J. Decreased natural killer cell activity in patients with zinc deficiency with sickle cell disease. J. Lab. Clin. Med. 1985, 105, 19-22.

47. Muzzioli, M.; Stecconi, R.; Moresi, R.; Provinciali, M. Zinc improves the development of human CD34+ cell progenitors towards NK cells and increases the expression of GATA-3 transcription factor in young and old ages. Biogerontology 2009, 10, 593-604. [CrossRef]

48. George, M.M.; Vignesh, K.S.; Landero Figueroa, J.A.; Caruso, J.A.; Deepe, G.S. Zinc induces dendritic cell tolerogenic phenotype and skews regulatory T Cell-Th17 balance. J. Immunol. 2016, 197, 1864-1876. [CrossRef]

49. Cnubben, N.H.P.; Rietjens, I.M.C.M.; Wortelboer, H.; van Zanden, J.; van Bladeren, P.J. The interplay of glutathione-related processes in antioxidant defense. Environ. Toxicol. Pharmacol. 2001, 10, 141-152. [CrossRef]

50. Ghezzi, P. Role of glutathione in immunity and inflammation in the lung. Int. J. Gen. Med. 2011, 4, 105-113. [CrossRef] [PubMed]

51. Enns, G.M.; Cowan, T.M. Glutathione as a Redox Biomarker in Mitochondrial Disease-Implications for Therapy. J. Clin. Med. 2017, 6, 50. [CrossRef]

52. Lomaestro, B.M.; Malone, M. Glutathione in Health and Disease: Pharmacotherapeutic Issues. Ann. Pharmacother. 1995, 29, 1263-1273. [CrossRef]

53. Morris, D.; Khurasany, M.; Nguyen, T.; Kim, J.; Guilford, F.; Mehta, R.; Gray, D.; Saviola, B.; Venketaraman, V. Glutathione and infection. Biochim. Et Biophys. Acta (Bba) Gen. Subj. 2013, 1830, 3329-3349. [CrossRef]

54. Aquilano, K.; Baldelli, S.; Ciriolo, M.R. Glutathione: New roles in redox signaling for an old antioxidant. Front. Pharmacol. 2014, 5, 196. [CrossRef]

55. Silvagno, F.; Vernone, A.; Pescarmona, G.P. The role of glutathione in protecting against the severe inflammatory response triggered by covid-19. Antioxidants 2020, 9, 624. [CrossRef]

56. Guloyan, V.; Oganesian, B.; Baghdasaryan, N.; Yeh, C.; Singh, M.; Guilford, F.; Ting, Y.S.; Venketaraman, V. Glutathione supplementation as an adjunctive therapy in COVID-19. Antioxidants 2020, 9, 914. [CrossRef]

57. Shi, Z.; Puyo, C.A. N-acetylcysteine to combat COVID-19: An evidence review. Ther. Clin. Risk Manag. 2020, 16, 1047-1055. [CrossRef]

58. Polonikov, A. Endogenous Deficiency of Glutathione as the Most Likely Cause of Serious Manifestations and Death in COVID-19 Patients. Acs Infect. Dis. 2020, 6, 1558-1562. [CrossRef] [PubMed]

59. Minich, D.M.; Brown, B.I. A review of dietary (Phyto)nutrients for glutathione support. Nutrients 2019, 11, 2073. [CrossRef]

60. Icard, P.; Lincet, H.; Wu, Z.; Coquerel, A.; Forgez, P.; Alifano, M.; Fournel, L. The key role of Warburg effect in SARS-CoV-2 replication and associated inflammatory response. Biochimie 2021, 180, 169-177. [CrossRef]

61. Serebrovska, Z.O.; Chong, E.Y.; Serebrovska, T.V.; Tumanovska, L.V.; Xi, L. Hypoxia, HIF-1 $\alpha$, and COVID-19: From pathogenic factors to potential therapeutic targets. Acta Pharmacol. Sin. 2020, 41, 1539-1546. [CrossRef]

62. Danta, C.C. SARS-CoV-2, Hypoxia, and Calcium Signaling: The Consequences and Therapeutic Options. Acs Pharmacol. Transl. Sci. 2021, 4, 400-402. [CrossRef] [PubMed]

63. Thaker, S.K.; Ch'ng, J.; Christofk, H.R. Viral hijacking of cellular metabolism. BMC Biol. 2019, 17, 59. [CrossRef]

64. Laviada-Molina, H.A.; Leal-Berumen, I.; Rodriguez-Ayala, E.; Bastarrachea, R.A. Working Hypothesis for Glucose Metabolism and SARS-CoV-2 Replication: Interplay Between the Hexosamine Pathway and Interferon RF5 Triggering Hyperinflammation. Role of BCG Vaccine? Front. Endocrinol. 2020, 11, 514. [CrossRef] [PubMed]

65. Mojzer, E.B.; Hrnčič, M.K.; Škerget, M.; Knez, Ž.; Bren, U. Polyphenols: Extraction methods, antioxidative action, bioavailability and anticarcinogenic effects. Molecules 2016, 21, 901. [CrossRef]

66. Zhang, H.; Tsao, R. Dietary polyphenols, oxidative stress and antioxidant and anti-inflammatory effects. Curr. Opin. Food Sci. 2016, 8, 33-42. [CrossRef]

67. Gonzalez-Alfonso, J.L.; Peñalver, P.; Ballesteros, A.O.; Morales, J.C.; Plou, F.J. Effect of $\alpha$-Glucosylation on the Stability, Antioxidant Properties, Toxicity, and Neuroprotective Activity of (-)-Epigallocatechin Gallate. Front. Nutr. 2019, 6, 30. [CrossRef]

68. Rasouli, H.; Farzaei, M.H.; Khodarahmi, R. Polyphenols and their benefits: A review. Int. J. Food Prop. 2017, $20,1700-1741$. [CrossRef] 
69. Yahfoufi, N.; Alsadi, N.; Jambi, M.; Matar, C. The Immunomodulatory and Anti-Inflammatory Role of Polyphenols. Nutrients 2018, 10, 1618. [CrossRef] [PubMed]

70. Paraiso, I.L.; Revel, J.S.; Stevens, J.F. Potential use of polyphenols in the battle against COVID-19. Curr. Opin. Food Sci. 2020, 32, 149-155. [CrossRef]

71. Ambriz-Pérez, D.L.; Leyva-López, N.; Gutierrez-Grijalva, E.P.; Heredia, J.B. Phenolic compounds: Natural alternative in inflammation treatment. A Review. Cogent Food Agric. 2016, 2, 1131412. [CrossRef]

72. Russo, M.; Moccia, S.; Spagnuolo, C.; Tedesco, I.; Russo, G.L. Roles of flavonoids against coronavirus infection. Chem. -Biol. Interact. 2020, 328, 109211. [CrossRef]

73. Kandere-Grzybowska, K.; Kempuraj, D.; Cao, J.; Cetrulo, C.L.; Theoharides, T.C. Regulation of IL-1-induced selective IL-6 release from human mast cells and inhibition by quercetin. Br. J. Pharmacol. 2006, 148, 208-215. [CrossRef]

74. Tutunchi, H.; Naeini, F.; Ostadrahimi, A.; Hosseinzadeh-Attar, M.J. Naringenin, a flavanone with antiviral and anti-inflammatory effects: A promising treatment strategy against COVID-19. Phytother. Res. 2020, 34, 3137-3147. [CrossRef]

75. Shi, Y.; Dai, J.; Liu, H.; Li, R.R.; Sun, P.L.; Du, Q.; Pang, L.L.; Chen, Z.; Yin, K.S. Naringenin inhibits allergen-induced airway inflammation and airway responsiveness and inhibits NF-kB activity in a murine model of asthma. Can. J. Physiol. Pharmacol. 2009, 87, 729-735. [CrossRef]

76. Miripour, Z.S.; Sarrami-Forooshani, R.; Sanati, H.; Makarem, J.; Taheri, M.S.; Shojaeian, F.; Eskafi, A.H.; Abbasvandi, F.; Namdar, N.; Ghafari, H.; et al. Real-time diagnosis of reactive oxygen species (ROS) in fresh sputum by electrochemical tracing; correlation between COVID-19 and viral-induced ROS in lung/respiratory epithelium during this pandemic. Biosens. Bioelectron. 2020, 165, 112435. [CrossRef] [PubMed]

77. Mironova, G.D.; Belosludtseva, N.V.; Ananyan, M.A. Prospects for the use of regulators of oxidative stress in the comprehensive treatment of the novel Coronavirus Disease 2019 (COVID-19) and its complications. Eur. Rev. Med Pharmacol. Sci. 2020, 24, 8585-8591. [CrossRef]

78. Bakadia, B.M.; Boni, B.O.O.; Ahmed, A.A.Q.; Yang, G. The impact of oxidative stress damage induced by the environmental stressors on COVID-19. Life Sci. 2021, 264, 118653. [CrossRef] [PubMed]

79. Suhail, S.; Zajac, J.; Fossum, C.; Lowater, H.; McCracken, C.; Severson, N.; Laatsch, B.; Narkiewicz-Jodko, A.; Johnson, B.; Liebau, J.; et al. Role of Oxidative Stress on SARS-CoV (SARS) and SARS-CoV-2 (COVID-19) Infection: A Review. Protein J. 2020, 39, 644-656. [CrossRef] [PubMed]

80. De las Heras, N.; Martín Giménez, V.M.; Ferder, L.; Manucha, W.; Lahera, V. Implications of Oxidative Stress and Potential Role of Mitochondrial Dysfunction in COVID-19: Therapeutic Effects of Vitamin D. Antioxidants 2020, 9, 897. [CrossRef] [PubMed]

81. Pormohammad, A.; Monych, N.K.; Turner, R.J. Zinc and SARS-CoV-2: A molecular modeling study of Zn interactions with RNA-dependent RNA-polymerase and 3C-like proteinase enzymes. Int. J. Mol. Med. 2021, 47, 326-334. [CrossRef]

82. Prasad, A.S. Lessons Learned from Experimental Human Model of Zinc Deficiency. J. Immunol. Res. 2020, $2020,9207279$. [CrossRef]

83. Shankar, A.H.; Prasad, A.S. Zinc and immune function: The biological basis of altered resistance to infection. Am. J. Clin. Nutr. 1998, 68, 447S-463S. [CrossRef] [PubMed]

84. Giovinazzo, G.; Gerardi, C.; Uberti-Foppa, C.; Lopalco, L. Can Natural Polyphenols Help in Reducing Cytokine Storm in COVID-19 Patients? Molecules 2020, 25, 5888. [CrossRef] [PubMed]

85. Santos, J.C.; Ribeiro, M.L.; Gambero, A. The Impact of Polyphenols-Based Diet on the Inflammatory Profile in COVID-19 Elderly and Obese Patients. Front. Physiol. 2021, 11, 1783. [CrossRef] [PubMed] 